\title{
A 20-year multicenter analysis of dialysis-dependent patients who had aortic or mitral valve replacement: Implications for valve selection
}

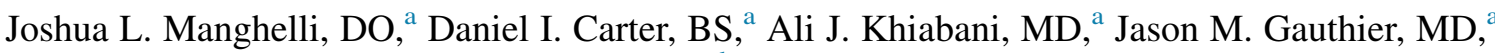
Marc R. Moon, MD, ${ }^{a}$ Nabil A. Munfakh, MD, ${ }^{b}$ Ralph J. Damiano, MD, ${ }^{a}$ Joel S. Corvera, $M D,{ }^{c}$ and Spencer J. Melby, MD ${ }^{\mathrm{a}}$

\section{ABSTRACT}

Objective: Valve selection in dialysis-dependent patients can be difficult because long-term survival is diminished and bleeding risks during anticoagulation treatment are greater in patients with renal failure. In this study we analyzed long-term outcomes of dialysis-dependent patients who underwent valve replacement to help guide optimal prosthetic valve type selection.

Methods: Dialysis-dependent patients who underwent aortic and/or mitral valve replacement at 3 institutions over 20 years were examined. The primary outcome was long-term survival. A Cox regression model was used to estimate survival according to 5 ages, presence of diabetes, and/or heart failure symptoms.

Results: Four hundred twenty-three available patients were analyzed; 341 patients had biological and 82 had mechanical valves. Overall complication and 30-day mortality rates were similar between the groups. Thirty-day readmission rates for biological and mechanical groups were 15\% (50/341) and 28\% (23/ $82 ; P=.005$ ). Five-year survival was $23 \%$ and $33 \%$ for the biological and mechanical groups, respectively. After adjusting for age, New York Heart Association (NYHA) class, and diabetes using a multivariable Cox regression model, survival was similar between groups (hazard ratio, $0.93 ; 95 \%$ confidence interval, $0.66-1.29 ; P=.8$ ). A Cox regression model on the basis of age, diabetes, and heart failure, estimated that patients only 30 or 40 years old, with NYHA class I-II failure without diabetes had a $>50 \%$ estimated 5-year survival $(P<.001)$.

Conclusions: Dialysis-dependent patients who underwent valve replacement surgery had poor long-term survival. Young patients without diabetes or NYHA III or IV symptoms might survive long enough to justify placement of a mechanical valve; however, a biological valve is suitable for most patients. (J Thorac Cardiovasc Surg 2019;158:805-13)

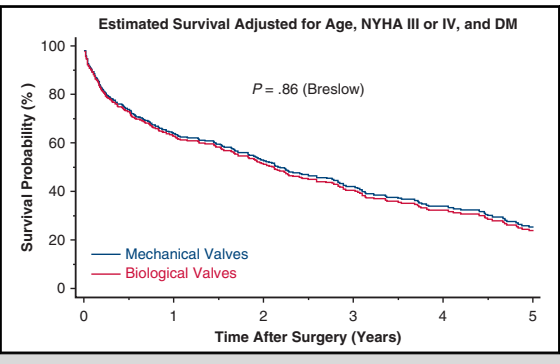

Estimated survival adjusted for age, NYHA III or IV, and DM.

\section{Central Message}

Most dialysis-dependent patients who undergo valve replacement have poor survival. Because survival is short, biological valves might be the more appropriate choice in most patients.

\section{Perspective}

There are few data to guide valve type selection in dialysis-dependent patients. Our findings show that long-term survival is poor in patients who undergo valve replacement surgery. Because of the short survival time, a biological valve is likely sufficient for most patients; however, young patients without diabetes or heart failure might survive long enough to justify placement of a mechanical valve.

See Commentaries on pages 814 and 816.

\footnotetext{
From the ${ }^{\mathrm{a}}$ Division of Cardiothoracic Surgery, Barnes-Jewish Hospital, ${ }^{\mathrm{b}}$ Division of Cardiothoracic Surgery, Christian Northeast Hospital, Washington University School of Medicine, St Louis, Mo; and ${ }^{\mathrm{c}}$ Division of Cardiothoracic Surgery, Indiana University School of Medicine, Methodist Hospital, Indianapolis, Ind.

This study was funded by National Institutes of Health T32-HL007776, Barnes-Jewish Hospital Foundation, and Veterans Affairs grant I01 CX001526.

Read at the 98th Annual Meeting of The American Association for Thoracic Surgery, San Diego, California, April 28-May 1, 2018.

Received for publication April 30, 2018; revisions received Oct 23, 2018; accepted for publication Oct 28, 2018; available ahead of print Jan 23, 2019

Address for reprints: Spencer J. Melby, MD, Division of Cardiothoracic Surgery, Barnes-Jewish Hospital, Washington University School of Medicine, Campus Box 8234, 660 S Euclid Ave, St Louis, MO 63110 (E-mail: smelby@wustl.edu). $0022-5223 / \$ 36.00$

Copyright $\odot 2018$ by The American Association for Thoracic Surgery https://doi.org/10.1016/j.jtcvs.2018.10.168
}

There are 120,000 cases of new end stage renal disease (ESRD) diagnosed every year and this number continues to rise. Approximately $90 \%$ of these patients receive hemodialysis. Mortality rates among dialysis patients remain

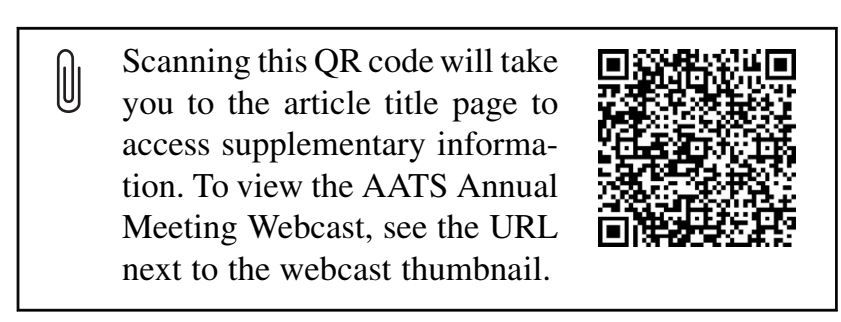




\section{Abbreviations and Acronyms \\ $\mathrm{ESRD}=$ end stage renal disease \\ IQR = interquartile range \\ NYHA $=$ New York Heart Association}

high. Overall 5-year survival for dialysis-dependent patients with ESRD is approximately $40 \%{ }^{1}$ Cardiovascular diseases comprise the leading cause of death in this patient population, as a result cardiac surgeons perform an increasing number of high-risk operations, including valve replacement surgery. ${ }^{1}$

There is debate about the optimal choice of prosthesis for valve replacement in dialysis-dependent patients. Early American Heart Association/American College of Cardiology guidelines (1998) recommended placement of mechanical valves in all dialysis-dependent patients who undergo valve replacement surgery. ${ }^{2}$ However, on the basis of small reports that showed equivalent outcomes in patients who received both types of valves, in 2006, the guidelines were revised and ceased to have explicit criteria for valve selection; the most current guidelines also do not give specific guidance. The most current recommendation is that valve selection should be individualized to the patient. ${ }^{3} \mathrm{Un}$ fortunately, there is a paucity of reports to aid in this selection process, because most studies have small samples sizes, are single-center, and/or are retrospective in nature.

Compared with mechanical valves, biological valves have poor longevity, which has been attributed to advanced calcification and degeneration. ${ }^{4}$ These processes are thought to be exacerbated by hematological changes in patients with ESRD; however, studies that have compared mechanical versus biological valves in hemodialysis-dependent patients have not shown a definitive survival advantage of one valve type $^{5-7}$ A prevailing challenge with mechanical valve replacement in the dialysis population is that these patients require frequent arteriovenous fistulae access and are more prone to major bleeding events. ${ }^{8}$ Because of the poor long-term survival of dialysis-dependent patients it is reasonable to believe that those who receive bioprosthetic valves might die before valve failure.

The purpose of this study was to compare postoperative outcomes and long-term survival of patients who required preoperative hemodialysis and underwent valve replacement surgery with either biological or mechanical valves. We hypothesized that most patients would not live long enough postoperatively to justify placement of a mechanical valve.

\section{METHODS}

Washington University and Indiana University institutional review boards approved the study (Washington University: 201802048, February 8, 2018; and Indiana University: 1708851013, September 13, 2017). All patients who were receiving preoperative hemodialysis who underwent mitral valve replacement or aortic valve replacement between January 1998 and August 2017 were identified retrospectively at 3 institutions located in the Midwest. Two institutions were major academic hospitals and 1 was a community hospital. The requirement for individual consent for this study was waived by the institutional review boards at each institution. Inclusion criteria included patients who underwent aortic and/or mitral valve replacement and required preoperative hemodialysis for $\geq 30$ days. Those who underwent transcatheter aortic valve replacement or aortic root replacement were excluded. EuroScore II was calculated on the basis of age, sex, renal impairment, extracardiac arteriopathy, poor mobility, previous cardiac surgery, chronic lung disease, active endocarditis, critical preoperative state, insulin-dependent diabetes, New York Heart Association (NYHA) class, left ventricular function, recent myocardial infarction, pulmonary hypertension, urgency of operation, weight of intervention, and surgery on thoracic aorta. If the data were not available the variable was omitted from the EuroScore II calculation. Preoperative diabetes does not distinguish between patients who were insulindependent.

The primary outcome measure was long-term survival. Secondary outcomes included estimated survival using a Cox regression model for 5 ages $(30,40,50,60$, and 70 years old) and presence or absence of diabetes mellitus and/or heart failure, 30-day mortality, hospital length of stay, ventilator hours, need for reoperation, and 30-day readmission rates. Survival data were obtained for all patients through interrogation of institutional medical records databases, obituaries, and the Social Security Death Index. Operative mortality was defined as death that occurred during the index hospitalization or within 30 days of the operation. Long-term survival data included death from all causes. The follow-up closing date was October 7, 2017.

The Shapiro-Wilk test was used to assess the distribution of the study population. To address missing data, multiple imputation was used. The expected maximization method was used for continuous variables and regression was used for categorical variables. Continuous data were reported as mean \pm standard deviation, or median (interquartile range [IQR]) as appropriate, and were compared between groups using the Student $t$ test and Mann-Whitney $U$ test, respectively. Categorical variables were compared using $\chi^{2}$ analysis. Survival estimates were generated using the KaplanMeier method and subsequently compared using the log rank test. Predictors of mortality were identified in univariable analysis using a $P$ value cutoff of .1 and then entered into a multivariable analysis. A multivariable Cox regression model was used to estimate survival on the basis of factors found to be significant for survival: age and the presence or absence of diabetes and/or NYHA III or IV symptoms. Propensity score matching using a caliper of 0.1 was performed using variables shown in Table 1. A logistic model with nearest neighbor algorithm, greedy method, and a 1:1 match was used. Variables selected included age, diabetes, EuroScore II, redo operation, valvulopathy, coronary artery disease, sex, endocarditis, hypertension, peripheral vascular disease, cerebrovascular disease, previous valve procedure, preoperative ejection fraction, and preoperative NYHA III or IV heart failure symptoms. Statistics were done using STATA version 15.0 (STATA Corp, College Station, Tex). A $P$ value of $\leq .05$ was considered statistically significant.

\section{RESULTS}

Four hundred ninety-two patients underwent valve replacement over the 20 -year period and 423 were included in the analysis. Sixty-nine patients were excluded because they underwent aortic root replacement or transcatheter aortic valve replacement. Three-hundred forty-one patients underwent replacement with a biological valve and 82 underwent replacement with a mechanical valve. There were 
TABLE 1. Preoperative characteristics of hemodialysis-dependent patients who underwent valve replacement with biologic or mechanical valves

\begin{tabular}{|c|c|c|c|}
\hline Variable & Biologic $(n=341)$ & Mechanical $(\mathbf{n}=\mathbf{8 2})$ & $P$ value \\
\hline \multicolumn{4}{|l|}{ Preoperative } \\
\hline Age, y & $60.1 \pm 13.5$ & $50.9 \pm 12.8$ & $<.001$ \\
\hline Female sex & $123(36)$ & $30(37)$ & .898 \\
\hline BMI & $29.2 \pm 7.8$ & $29.9 \pm 8.2$ & .581 \\
\hline White race & $222(65)$ & $50(62)$ & .605 \\
\hline Euro Score II & $9.43 \pm 7.86$ & $6.79 \pm 6.71$ & .002 \\
\hline NYHA class III or IV & $234(68)$ & $54(66)$ & .872 \\
\hline Ejection fraction & $50.8 \pm 14.9$ & $53.5 \pm 14.9$ & .170 \\
\hline Smoker & $141(42)$ & $38(47)$ & .885 \\
\hline HTN & $304(89)$ & $73(90)$ & .845 \\
\hline Cerebrovascular disease & $93(27)$ & $15(18)$ & .062 \\
\hline Dyslipidemia & $201(59)$ & $40(48)$ & .112 \\
\hline Diabetes & $159(46)$ & $32(40)$ & .267 \\
\hline PVD & $103(30)$ & $16(20)$ & .074 \\
\hline Chronic lung disease & $107(31)$ & $19(23)$ & .070 \\
\hline Previous sternotomy & $81(23)$ & $14(17)$ & .239 \\
\hline Previous valve operation & $54(15)$ & $11(13)$ & .731 \\
\hline Endocarditis & $121(35)$ & $24(30)$ & .364 \\
\hline \multicolumn{4}{|l|}{ Intraoperative } \\
\hline AVR & 211 & 42 & N/A \\
\hline MVR & 89 & 28 & \\
\hline Two or more valves & 41 & 12 & \\
\hline AVR + MVR & 39 & 10 & \\
\hline $\mathrm{AVR}+\mathrm{MVR}+\mathrm{TVR}$ & 1 & 0 & \\
\hline $\mathrm{AVR}+\mathrm{TVR}$ & 1 & 1 & \\
\hline MVR + TVR & 0 & 1 & \\
\hline Cross clamp time, minutes & $118.8 \pm 57$ & $127.0 \pm 64$ & .301 \\
\hline CPB time, minutes & $169.4 \pm 76$ & $185.38 \pm 90$ & .148 \\
\hline Tricuspid valve procedure & $28(8)$ & $8(10)$ & .36 \\
\hline Concomitant $\mathrm{CABG}$ & $96(28)$ & $15(18)$ & .092 \\
\hline
\end{tabular}

Bold indicates significant values with $P$ value $<.05$. Numbers are represented as mean \pm standard deviation or number $(\%) . B M I$, Body mass index; NYHA, New York Heart Association; $H T N$, hypertension; $P V D$, peripheral vascular disease; $A V R$, aortic valve replacement; $M V R$, mitral valve replacement; $T V R$, tricuspid valve repair or replacement; $C P B$, cardiopulmonary bypass; $C A B G$, coronary artery bypass.

no patients who had undergone preoperative kidney transplantation. One-hundred forty nine $(35 \%)$ were from Indiana University, $196(46 \%)$ were from Barnes-Jewish Hospital, and $80(18 \%)$ were from Christian Northeast Hospital. Median follow-up was 1.28 (interquartile range, $0.2-3.1$ ) years, and survival data were available for $81 \%$ of patients. Baseline preoperative characteristics are summarized in Table 1. The average age for patients who had biological valves was $60 \pm 13.5$ and $51 \pm 12.8$ years for patients who had mechanical valves placed $(P<.001)$. The average EuroScore II was $12.3 \pm 7.8 \%$ and $8.9 \pm 6.7 \%$ for the biological valve and mechanical valve groups, respectively $(P=.002)$. Eighty-one $(23 \%)$ and $14(17 \%)$ of the biological and mechanical valve groups were reoperations, respectively. More specifically, $54(15 \%)$ of the biological valve group had a previous valve operation and $11(13 \%)$ of the mechanical valve group had a previous valve operation. There were no significant differences between evaluated intraoperative variables (Table 1). Overall complication and 30-day mortality rates were similar between groups (Table 2). However, 23 of $82(28 \%)$ patients in the mechanical valve group were readmitted within 30 days compared with 50 of $341(15 \%)$ in the biological valve group $(P=.005)$. Regarding 30 -day mortality, the cause of mortality was available for 40 of 55 patients. Of these patients, 20 died from a cardiac-related cause, 5 were pulmonary-related, 5 were neurologic, 1 was vascular, and 10 were sepsis-related.

Presence of diabetes mellitus, age, and NYHA III or IV symptoms were all significant predictors of mortality 
TABLE 2. Postoperative outcomes of dialysis-dependent patients who underwent valve replacement with biological or mechanical valves

\begin{tabular}{lccc}
\hline \multicolumn{1}{c}{ Variable } & $\begin{array}{c}\text { Biologic } \\
(\mathbf{n = 3 4 1 )}\end{array}$ & $\begin{array}{c}\text { Mechanical } \\
(\mathbf{n = 8 2})\end{array}$ & $\boldsymbol{P}$ value \\
\hline Ventilator hours & $33[10-118]$ & $19[10-117]$ & .081 \\
Reoperation for bleeding & $16(5)$ & $5(6)$ & .572 \\
Sepsis & $42(12)$ & $5(6)$ & .167 \\
Stroke & $14(4)$ & $4(5)$ & .759 \\
\hline Atrial fibrillation & $109(32)$ & $23(28)$ & .595 \\
Length of stay & $13[5,21]$ & $13[8,22]$ & .632 \\
\hline 30-Day mortality & $47(14)$ & $8(10)$ & .462 \\
30-Day readmission & $50(15)$ & $23(28)$ &. $\mathbf{0 0 5}$ \\
\hline Readmission for bleeding & $6 / 70(8.5)$ & $10 / 70(14)$ & .084 \\
\hline D
\end{tabular}

Data are presented as median [interquartile range] or as number $(\%)$.

(Table 3). Having 2 or more valves replaced was not a predictor of poor outcomes (hazard ratio, $0.873 ; 95 \%$ confidence interval, $0.625-1.220 ; P=.43$ ) as indicated in the univariable Cox analysis. On the basis of Kaplan-Meier analysis, 5 -year survival was $23 \%$ for the biological valve group and $33 \%$ for the mechanical valve group. Ten-year survival was $5 \%$ and $20 \%$ with a median survival of 2.06 (IQR, 1.56-2.36) and 3.02 (IQR, 1.69-4.34) years for the biological and mechanical groups, respectively $(P=.017$; Figure 1). No patients in either group survived longer than 13 years (Figure 2). When adjusted for age, NYHA class, and diabetes using a multivariable Cox regression model, survival was similar between groups (hazard ratio, $0.93 ; 95 \%$ confidence interval, $0.66-1.29 ; P=.86$; Figure 3). Propensity score matching yielded 75 patients in the biological valve group and 75 patients in the mechanical valve group (Figures E1-E4). Survival was similar in each group (Figure E4). Patients who received a biological valve spent significantly more hours on the ventilator (Table E1).

A Kaplan-Meier analysis of patients with and without endocarditis showed a 5-year survival of $25 \%$ and $25 \%$, respectively $(P=.591)$. Cox regression using variables found to be significant for long-term survival was used to estimate 5-year survival on the basis of 5 ages (30, 40, 50, 60 , and 70 years), diabetes, and NYHA class $\geq 3$ $(P<.001$; Figure 4 , Table 4$)$. Only patients who were 30 or 40 years old and in NYHA class I/II failure without diabetes had a $>50 \%$ estimated 5-year survival (Harrell C coefficient, 0.61; Table 4).

\section{DISCUSSION}

Most hemodialysis patients who underwent valve replacement surgery had poor long-term survival. At 5 years postoperatively, only $23 \%$ and $33 \%$ of patients were alive in the biological and mechanical groups, respectively. These findings are similar to previous smaller studies. Brinkman and colleagues showed that overall survival of patients who underwent dialysis at 6 years was $15.9 \%$ in a cohort of 72 patients, ${ }^{9}$ and Zhibing and colleagues showed

TABLE 3. Univariable and multivariable predictors of mortality after valve replacement in patients with end stage renal disease who required hemodialysis

\begin{tabular}{|c|c|c|c|c|}
\hline \multirow[b]{2}{*}{ Variable } & \multicolumn{2}{|c|}{ Univariable analysis } & \multicolumn{2}{|c|}{ Multivariable analysis } \\
\hline & Hazard ratio $(95 \%$ CI $)$ & $P$ value & Hazard ratio $(95 \% \mathrm{CI})$ & $P$ value \\
\hline Age & $1.03(1.02-1.04)$ & $<.001$ & $1.09(1.011-1.11)$ & $<.001$ \\
\hline Sex & $1.02(0.96-1.53)$ & .13 & & \\
\hline Race & $1.02(0.91-1.52)$ & .24 & & \\
\hline BMI & $1.00(0.99-1.03)$ & .42 & & \\
\hline EuroScore II & $1.01(1.00-1.05)$ & .14 & & \\
\hline NYHA class III or IV & $1.39(1.03-1.89)$ & .033 & $1.36(1.01-1.82)$ & .048 \\
\hline Ejection fraction & $0.98(0.97-0.99)$ & .12 & & \\
\hline Smoker & $1.10(0.97-1.61)$ & .17 & & \\
\hline HTN & $0.91(0.62-1.33)$ & .64 & & \\
\hline CVD & $1.03(0.85-1.40)$ & .50 & & \\
\hline Dyslipidemia & $1.00(0.78-1.30)$ & .97 & & \\
\hline PVD & $0.76(0.61-0.99)$ & .14 & & \\
\hline Chronic lung disease & $0.91(0.72-1.16)$ & .91 & & \\
\hline Previous sternotomy & $0.79(0.61-1.04)$ & .11 & & \\
\hline Previous valve & $0.86(0.62-1.20)$ & .86 & & \\
\hline Endocarditis & $1.21(0.89-1.52)$ & .30 & & \\
\hline Diabetes & $1.41(1.25-1.63)$ & .001 & $1.54(1.21-2.01)$ & .001 \\
\hline
\end{tabular}




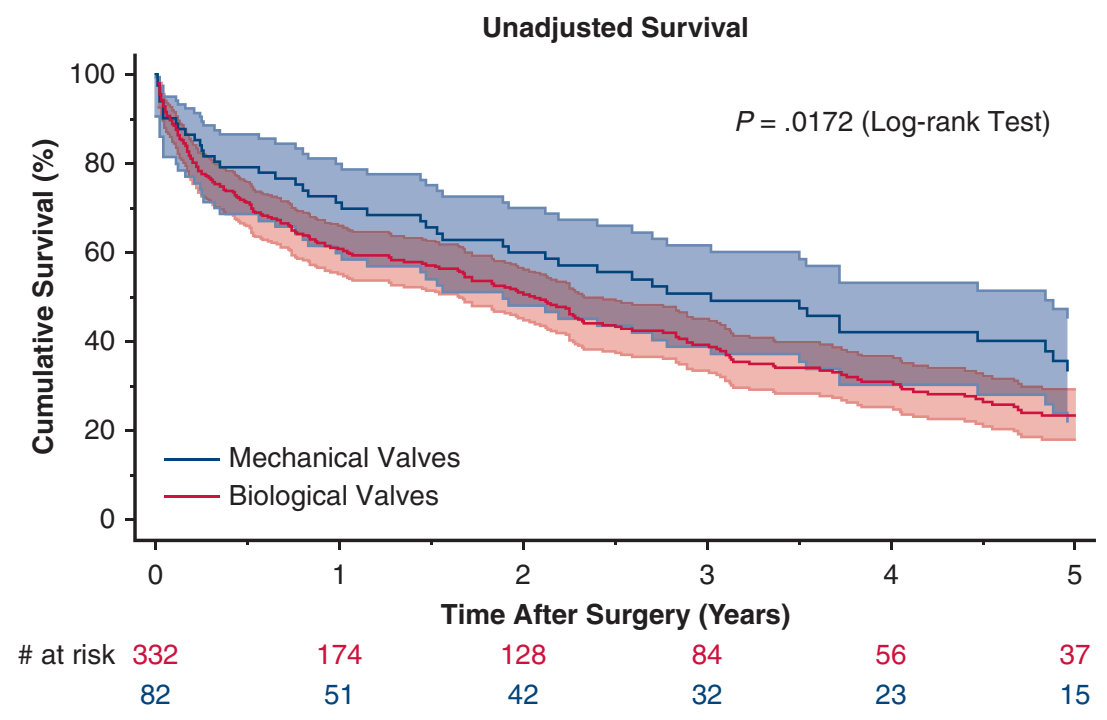

FIGURE 1. Unadjusted Kaplan-Meier analysis for dialysis-dependent patients who underwent valve replacement with mechanical versus biological valves.

an estimated 5-year patient survival rate with bioprosthetic valves of $53 \%$ versus $56.8 \%$ with mechanical valves in 73 dialysis-dependent patients who had undergone surgery. ${ }^{4}$

Cardiovascular disease remains the most common cause of death in patients who require dialysis. This patient population represents an ongoing challenge to physicians because they are high-risk surgical candidates. ${ }^{1}$ Valve selection in dialysis patients presents a dilemma to cardiac surgeons because they must assess the risk for accelerated bioprosthetic valve deterioration due to calcification against the morbidity and mortality associated with anticoagulation. ${ }^{4,10,11}$ Anticoagulation in this patient population can be problematic, especially in those who require vascular access several times per week. Furthermore, they must assess these risks and benefits in the face of known poor long-term survival. Previous guidelines established in 1998 from the American College of Cardiology and American Heart Association recommended placement of mechanical heart valve prostheses for patients with ESRD who require dialysis. ${ }^{2}$ These recommendations were on the basis of concern for accelerated calcification of bioprosthetic valves. However, several studies subsequently

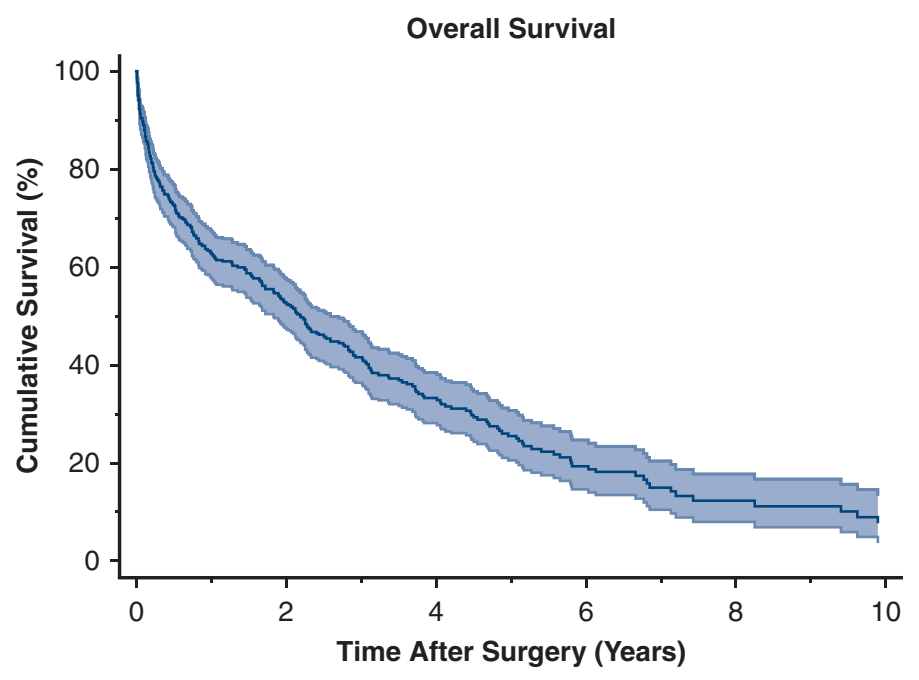

Number at risk $414 \quad 170$ 79 32 11 7

FIGURE 2. Overall survival of dialysis-dependent patients who underwent valve replacement surgery with biological and/or mechanical valves; 423 patients were included in the analysis. 


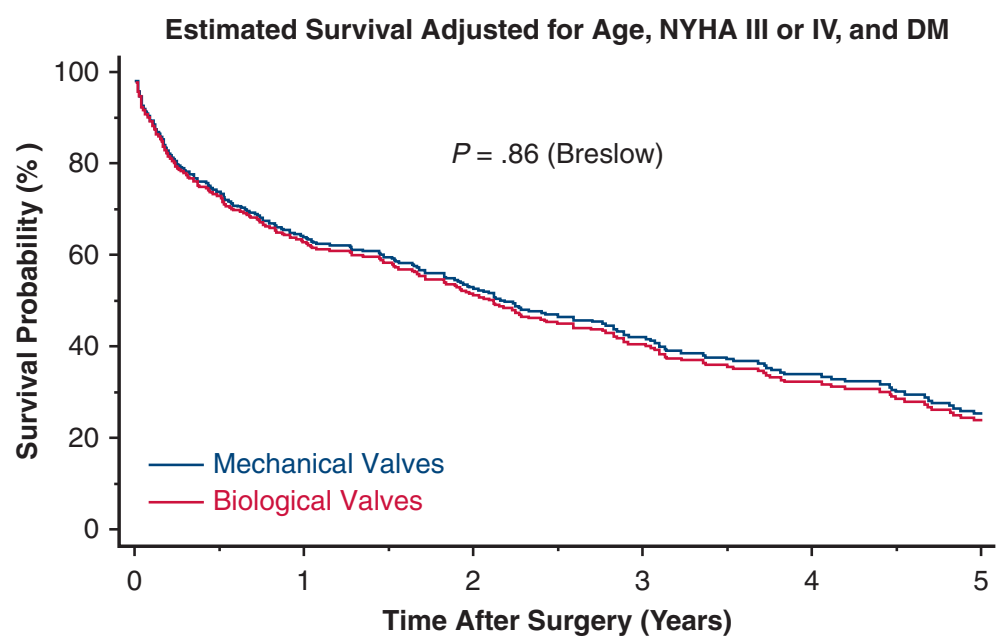

FIGURE 3. Cox regression analysis for patients who underwent valve replacement. Estimation of 5 -year survival was generated using a Cox regression analysis. Variables included in this model were age, New York Heart Association (NYHA) class III or IV symptoms, and presence of diabetes (DM), which were all significant predictors of mortality.

have shown that there was no difference in survival between patients who received mechanical versus biological prostheses. ${ }^{4,9,12-15}$ The most notable study done by Herzog and colleagues retrospectively identified 5858 dialysis patients who underwent heart valve replacement surgery from the US Renal Data System database. It showed that survival with tissue prosthetic valves at 5 years was $13.8 \%$ versus $14.9 \%$ in patients who received mechanical valves. ${ }^{5}$ The guidelines were subsequently updated in 2006 and 2014, and they no longer have specific recommendations for valve selection in this patient population. It is recommended to individualize prosthesis selection. However, choice of valve type remains difficult because there are limited data defining long-term survival in this population. ${ }^{3,12}$

Our findings of very poor long-term survival ( $13 \%$ overall at 10 years) mirrors the US Renal Data System estimation of survival as well as other studies. ${ }^{16,17}$ After adjusting for age, NYHA class, and diabetes there was no difference in survival between those who had biological valves, or those who had mechanical valves placed in this current study. Furthermore, propensity score matching corroborated our multivariable analysis.

To delineate who might live long enough to warrant a mechanical valve, a Cox regression analysis was performed to estimate survival on the basis of 5 different ages $(30,40,50$,

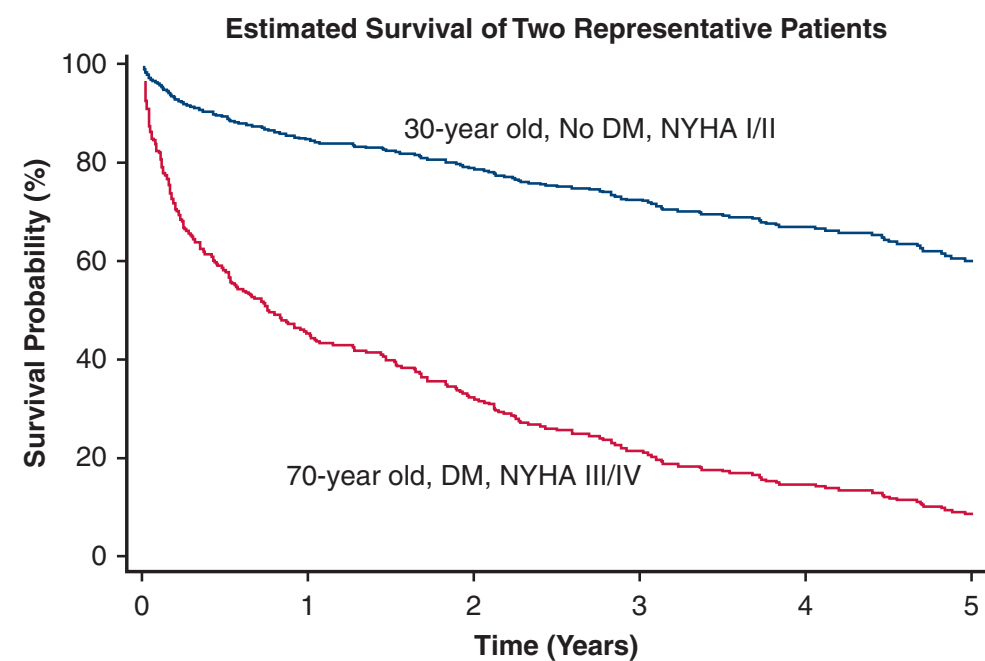

FIGURE 4. Patient plots showing estimated survival for a 30-year-old dialysis-dependent patient without diabetes $(D M)$ and New York Heart Association (NYHA) class III or IV heart failure symptoms and a 70-year-old dialysis-dependent patient with diabetes and NYHA class III or IV symptoms after valve replacement using a Cox regression analysis $(P<.001)$. 
TABLE 4. Estimated 5-year survival based on the basis of 5 age groups $(P<.001$; HR, 1.09 [95\% CI, 1.01-1.11]), diabetes $(P<.001$; HR, 1.54 [95\% CI, 1.21-2.01]), and/or NYHA heart failure symptoms $(P=.048$; HR, 1.36 [95\% CI,1.01-1.82])

\begin{tabular}{|c|c|c|c|c|}
\hline \multirow[b]{2}{*}{ Age group } & \multicolumn{2}{|c|}{ No diabetes } & \multicolumn{2}{|c|}{ Diabetes } \\
\hline & $\begin{array}{c}\text { NYHA } \\
\text { I-II }\end{array}$ & $\begin{array}{l}\text { NYHA } \\
\text { III-IV }\end{array}$ & $\begin{array}{c}\text { NYHA } \\
\text { I-II }\end{array}$ & $\begin{array}{l}\text { NYHA } \\
\text { III-IV }\end{array}$ \\
\hline 30 Years & 61 & 50 & 46 & 35 \\
\hline 40 Years & 54 & 43 & 38 & 27 \\
\hline 50 Years & 46 & 34 & 30 & 19 \\
\hline 60 Years & 35 & 27 & 22 & 13 \\
\hline 70 Years & 31 & 19 & 16 & 8 \\
\hline
\end{tabular}

Data are presented as percentages. NYHA, New York Heart Association.

60 , or 70 years), and the presence of diabetes and/or heart failure. Only patients aged 30 or 40 years in NYHA class I/II failure without diabetes had a $>50 \%$ estimated 5 -year survival (Figure 4, Table 4). In our study, this represented only 24 patients, or $7 \%$ of the total group of 423 . In our model, a physician can evaluate a patient on the basis of age, and presence of diabetes or heart failure and gain insight regarding survival after valve replacement. This model might help guide valve selection in this complicated group of patients. Larger prospective studies are needed to corroborate our findings.

In our study $15 \%$ of patients with biological valves were readmitted versus $28 \%$ of patients with mechanical valves within 30 days of discharge. Of those who had a known reason for readmission, 10 of $70(14 \%)$ in the mechanical valve group were readmitted for bleeding complications versus 6 of $70(8.5 \%)$ in the biological valve group. Most bleeding complications occurred within the first few months of initiation of anticoagulation. Because anticoagulation carries an increased risk of morbidity and inconveniences these patients, mechanical valves should be reserved only for those with an estimated long-term survival that is longer than the time a biological valve might deteriorate. This study suggests that only very young people (eg, 30-40 years old) without diabetes or NYHA III or IV symptoms have a high enough estimated survival to warrant consideration of a mechanical valve and anticoagulation.

The limitations of this study include that it was retrospective in nature and thus subject to the threats inherent to this design. Furthermore, because no standardized protocols were used for the selection of valve type, surgeon bias likely influenced the data. We had limited echocardiographic data to confirm the longevity of valves. Because of limitations of databases and data accrual from a multi-institutional study, follow-up of patients was not $100 \%$ complete, which limits the accuracy of results. However, estimated survival rates were highly statistically significant, which indicates sufficient numbers were available for estimation of long-term mortality. A larger prospective randomized study would be needed to corroborate our results.

\section{CONCLUSIONS}

Patients who require dialysis and undergo valve replacement surgery have poor long-term survival. Valve type must ultimately be tailored to each patient. Because most patients have very poor short-term $(<5$ year $)$ survival, biological valves should be strongly considered. In our model, only young patients (age 30 or 40 years), without diabetes or NYHA III or IV symptoms had an estimated 5-year survival $>50 \%$; therefore, only in this small segment of the overall population might it be justifiable to place a mechanical valve.

\section{Webcast}

You can watch a Webcast of this AATS meeting presentation by going to: https://aats.blob.core.windows.net/ media/18Apr30/20ABC $\% 202$.Adult $\% 20$ Cardiac $\% 20$ SS/ S62_3.mp4.

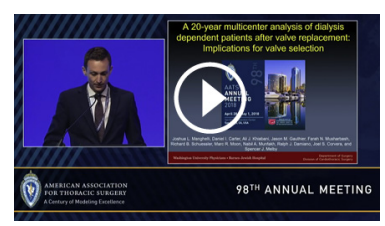

\section{Conflict of Interest Statement}

R.J.D. discloses Atricure: consultant, speaker, and research funding; LivaNova: speaker; Medtronic: consultant; and Edwards Lifesciences: speaker. All other authors have nothing to disclose with regard to commercial support.

\section{References}

1. United States Renal Data System. 2018 Annual Data Report. Available at: http:// www.usrds.org/adr.htm. Accessed October 2017.

2. ACC/AHA guidelines for the management of patients with valvular heart disease. A report of the American College of Cardiology/American Heart Association. Task force on practice guidelines (Committee on Management of Patients with Valvular Heart Disease). J Am Coll Cardiol. 1998;32:1486-588.

3. Nishimura RA, Otto CM, Bonow RO, Carabello BA, Erwin JP 3rd, Guyton RA, et al. 2014 AHA/ACC guideline for the management of patients with valvular heart disease: a report of the American College of Cardiology/American Hear Association task force on practice guidelines. Circulation. 2014;129:e521-643.

4. Zhibing Q, Chen X, Ming X, Lele L, Yingshuo J, LiMing W. Should bioprostheses be considered the valve of choice for dialysis-dependent patients. J Cardiothorac Surg. 2013;8:42.

5. Herzog C, Jennie Z, Collins A. Long-term survival of dialysis patients in the United States with prosthetic heart valves: should ACC/AHA practice guidelines on valve selection be modified? Circulation. 2002;105:1336-41.

6. Gelsomino S, Morocutti G, Gianluca M, Cheli G, Poldini F, Da Broi U, et al. Open heart surgery in patients with dialysis-dependent renal insufficiency J Card Surg. 2001;16:400-7.

7. Kaplon RJ, Cosgrove DM III, Gillinov AM, Lytle BW, Blackstone EH, Smedira NG. Cardiac valve replacement in patients on dialysis: influence of prosthesis on survival. Ann Thorac Surg. 2000;70:438-41.

8. Holden RM, Harman GJ, Wang M, Holland D, Day AG. Major bleeding in hemodialysis patients. Clin J Am Soc Nephrol. 2008;3:105-10.

9. Brinkman WT, Williams WH, Guyton RA, Jones EL, Craver JM. Valve replacement in patients on chronic renal dialysis: implications for valve prosthesis selection. Ann Thorac Surg. 2002;74:37-42. 
10. Lewandowski TJ, Armstrong WF, Bolling SF, Bach DS. Calcification and degeneration following mitral valve reconstruction in patients requiring chronic dialysis. J Heart Valve Dis. 2000;9:364-9.

11. Umana E, Ahmed W, Alpert MA. Valvular and perivalvular abnormalities in endstage renal disease. Am J Med Sci. 2003;325:237-42.

12. Chan V, Chen L, Mesana L, Mesana TG, Ruel M. Heart valve prosthesis selection in patients with end-stage renal disease requiring dialysis: a systematic review and meta-analysis. Heart. 2011;97:2033-7.

13. Lucke JC, Samy RN, Atkins BZ, Silvestry SC, Douglas JM Jr, Schwab SJ, et al. Results of valve replacement with mechanical and biological prostheses in chronic renal dialysis patients. Ann Thorac Surg. 1997;64:129-32; discussion: $132-3$.

14. Filsoufi F, Chikwe J, Castillo JG, Rahmanian PB, Vassalotti J, Adams DH. Prosthesis type has minimal impact on survival after valve surgery in patients with moderate to end-stage renal failure. Nephrol Dial Transplant. 2008;23:3613-21.

15. Umezu K, Saito S, Yamazaki K, Kawai A, Kurosawa H. Cardiac valvular surgery in dialysis patients: comparison of surgical outcome for mechanical versus bioprosthetic valves. Gen Thorac Cardiovasc Surg. 2009;57: 197-202.

16. Tanaka K, Tajima K, Takami Y, Okada N, Terazawa S, Usui A, et al. Early and late outcomes of aortic valve replacement in dialysis patients. Ann Thorac Surg. 2010;89:65-70.

17. Chan V, Jamieson WR, Fleisher AG, Denmark D, Chan F, Germann E. Valve replacement surgery in end-stage renal failure: mechanical prostheses versus bioprostheses. Ann Thorac Surg. 2006;81:857-62.

Key Words: dialysis, valve replacement, renal failure

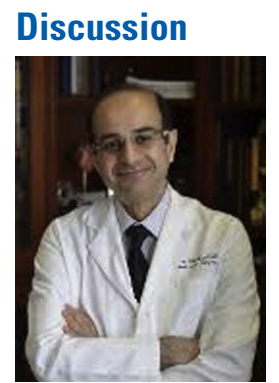

Dr Farzan Filsoufi (New York, NY). Nice job, nice presentation, Josh. In 2017 , there were close to 700,000 patients on dialysis in the United States. Although the incidence of end stage renal disease has plateaued, the dialysis population is growing by about 21,000 additional patients annually owing to the decrease in mortality among these patients. With the rising number of patients and declining mortality of dialysis patients, the number of dialysis patients with valvular heart disease, and particularly aortic stenosis, is projected to increase. In the United States, the utilization of aortic valve replacement in dialysis patients with aortic stenosis increased threefold between 2005 and 2014; most of these patients actually underwent TAVR. Valvular surgery in patients with renal failure on dialysis remains challenging, as you mentioned and according to your data. I would like to congratulate you and your colleagues for your good outcomes. In 2008 we published our own experience at Mount Sinai and reported similar results. We agree with your conclusion that the use of a biological valve is justified in the majority of patients with dialysis because of their limited life expectancy.

Josh, if I may, I am going to ask you a few questions. You excluded patients who underwent TAVR in your study. In a recent publication based on a nationwide inpatient sample database, after propensity matching, in-hospital mortality was twofold higher after SAVR compared with TAVR; it was $13 \%$ in patients who underwent surgery versus $6 \%$ of patients who underwent TAVR. So my first question is, in your practice, have you seen any shift toward TAVR instead of SAVR? And the second part of my question is, what criteria do you currently use to select patients with aortic stenosis for SAVR versus TAVR in dialysis patients?

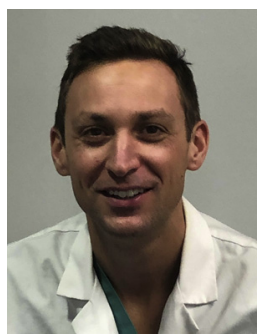

Dr Joshua Manghelli (St Louis, Mo). Thank you, Dr Filsoufi, for discussing our paper. We recognize that you have done a lot of work in this area, including the paper you just mentioned, which you published about 10 years ago of 155 . You showed that survival was not different between patients who received biological versus mechanical valves. So, again, I want to reiterate that in our study we showed that the majority of patients had an estimated 5-year survival of less than $40 \%$. We should ask: should we consider biological valves in the majority of these patients? So then, as you are alluding to, the question arises, should TAVR or surgical AVR be performed? I think it's completely reasonable to consider TAVR in these patients with some considerations. For example, these patients may have access issues. I think those patients might be excluded. Ultimately, I think you have to individualize your treatment options in these patients.

We have seen a shift at Barnes Hospital toward TAVR, but I think we have to keep the aforementioned caveats in mind.

Dr Filsoufi. My second question is alluding to the longterm survival in your younger group of patients. As you mentioned, the 5-year survival is very poor, and even in your Cox regression analysis only younger patients who were within 30 and 40 years of age with no diabetes and heart failure, their estimated 5-year survival was $>50 \%$.

So with all this information, what do you think of a strategy of a broader application of SAVR and biological valve for the first operation with the perspective of TAVR with a valve-in-valve procedure for the second and eventually third intervention?

Dr Manghelli. That's a great question as well. Again, I think it boils down to 3 options; you can perform a mechanical valve replacement, TAVR, or surgical AVR, and that's going to have to be a discussion with your team. If you think that patient is going to live long enough to justify placement of a mechanical valve and your team is willing to deal with the anticoagulation that entails, that's not a bad option. With that said, I think if you were going to pursue a biological valve and the patient will not have difficult access, then TAVR is a good option in many patients.

Dr Filsoufi. My third question is for dialysis patients who are candidates for kidney transplantation. In my practice, in a great number of these patients their valvular heart disease 
is discovered during the workup for transplantation. And then you have this dilemma of should we put a tissue valve in these patients to avoid all anticoagulation problems during a kidney transplant, particularly if they have a living donor, or you would say among some of our physicians that if you put a kidney transplantation, the survival of these patients is significantly increased, and particularly in the younger group, like 40, they would suggest an insertion of a mechanical valve.

So I would like to know, how does the perspective of a kidney transplantation affect your decision-making process and how many of your patients went on to get a kidney transplantation and what were their long-term outcomes?

Dr Manghelli. That's a great question. In our study we didn't specifically address this. Most of the patients had end stage renal disease, on dialysis, but they were not awaiting kidney transplantation. However, I think this is a realworld issue, and again, I think you have 3 options: a mechanical valve, a surgical valve, or TAVR. If you think the patient is going to undergo a kidney transplantation and live long enough to justify placement of a mechanical valve, I think it's completely reasonable to do so if everyone on your team is on board to handle everything that entails, such as the anticoagulation.
Dr Filsoufi. Finally, my last question is regarding the choice of the mechanical valve in dialysis patients. I would like to know if you have any experience within your generation of mechanical valves that require lower anticoagulation levels and what is your current strategy in terms of the amount of anticoagulation with a mechanical valve on dialysis patients?

Dr Manghelli. Sorry, are you referring to the On-X valve?

Dr Filsoufi. The On-X valve.

Dr Manghelli. We don't have information specifically about this valve. We have favored this valve for several years, given that in some low-risk patients the anticoagulation levels can be lower. However, a significant issue is that you have to anticoagulate fully for 3 months anyway. Looking at our readmission data, mechanical valve patients were readmitted twice as often within 30 days, often due to bleeding.

Dr Filsoufi. In the aortic position do you keep an INR below 2 or do you have the tendency to keep them above 2 ?

Dr Manghelli. In the aortic position, 2 to 2.5 .

Dr Filsoufi. Even with the On-X valve?

Dr Manghelli. With the On-X valve, no, not in low-risk patients. You can have a lower INR, 1.5 to 2.0. 


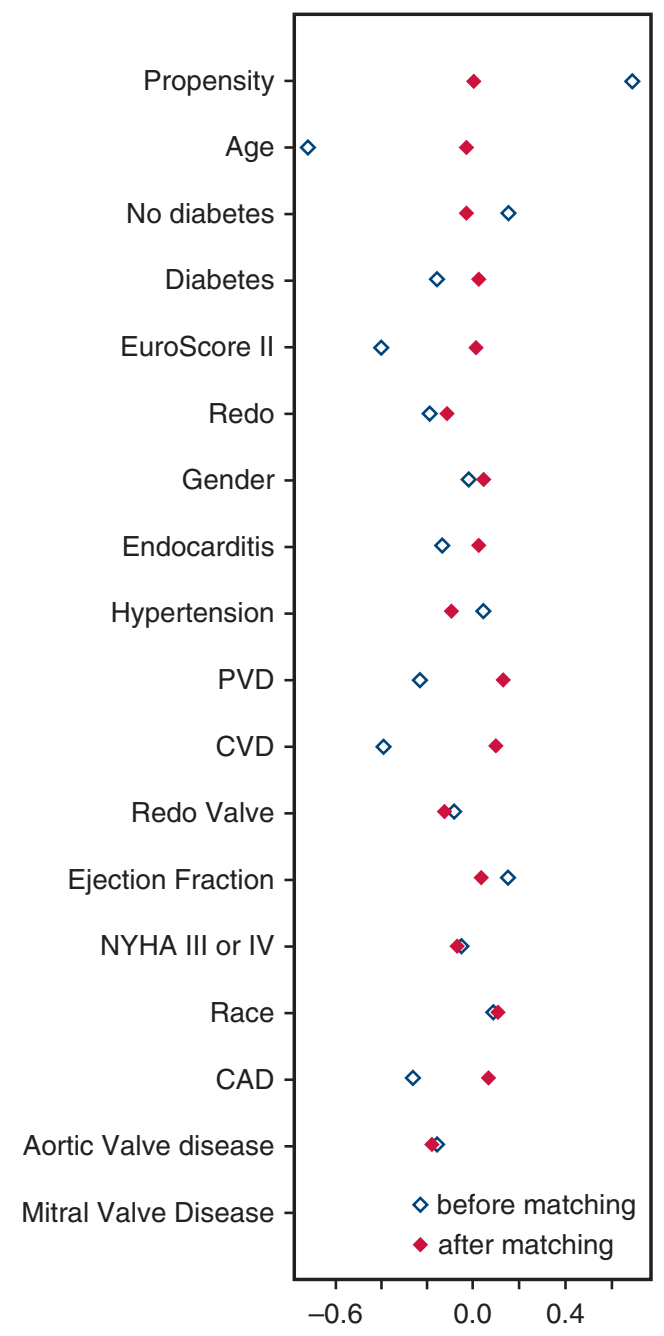

FIGURE E1. Variables included in the propensity analysis and their before and after matching standardized differences. $P V D$, Peripheral vascular disease; $C V D$, cerebrovascular disease; NYHA, New York Heart Association; $C A D$, coronary artery disease.

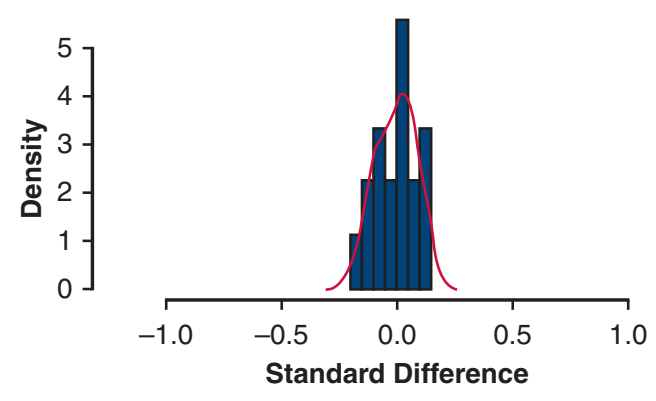

FIGURE E3. Standard differences after propensity matching.

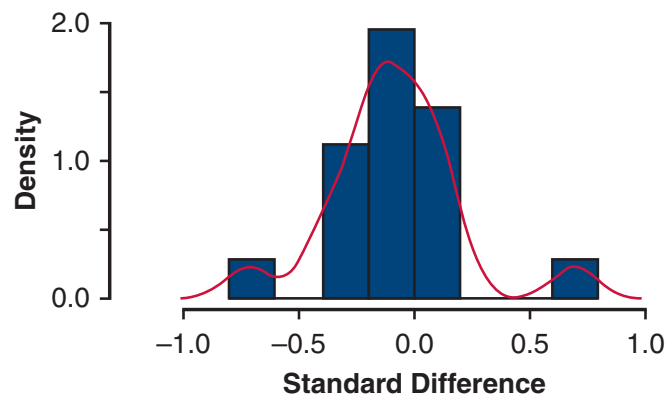

FIGURE E2. Standard differences before propensity matching. 


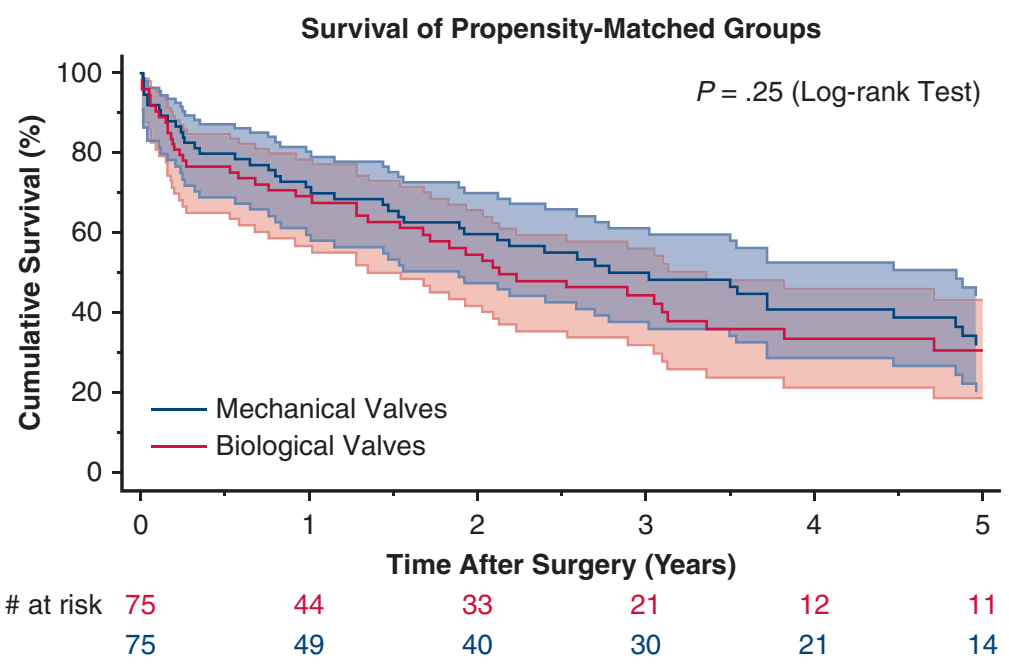

FIGURE E4. Survival analysis of propensity-matched groups using the Kaplan-Meier method.

TABLE E1. Postoperative outcomes of propensity-matched patients

\begin{tabular}{lccc}
\hline \multicolumn{1}{c}{ Variable } & $\begin{array}{c}\text { Biologic } \\
(\mathbf{n = 7 5 )}\end{array}$ & $\begin{array}{c}\text { Mechanical } \\
(\mathbf{n}=\mathbf{7 5})\end{array}$ & $\boldsymbol{P}$ value \\
\hline Ventilator hours & $88[15-130]$ & $25[9-130]$ & $\mathbf{. 0 3 0}$ \\
Reoperation for bleeding & $4(5)$ & $5(7)$ & 1.00 \\
\hline Sepsis & $12(16)$ & $5(7)$ & .12 \\
Stroke & $3(4)$ & $4(5)$ & 1.00 \\
Atrial fibrillation & $25(33)$ & $23(31)$ & .86 \\
Length of stay & $13[7-26]$ & $13[8-19]$ & .85 \\
\hline 30-Day mortality & $8(11)$ & $6(8)$ & .78 \\
30-Day readmission & $10(13)$ & $21(28)$ & $\mathbf{. 0 4 3}$ \\
\hline
\end{tabular}

Data are presented as median [Interquartile range] or number $(\%)$. Numbers in bold indicate significant values with $P$ value $<.05$. 